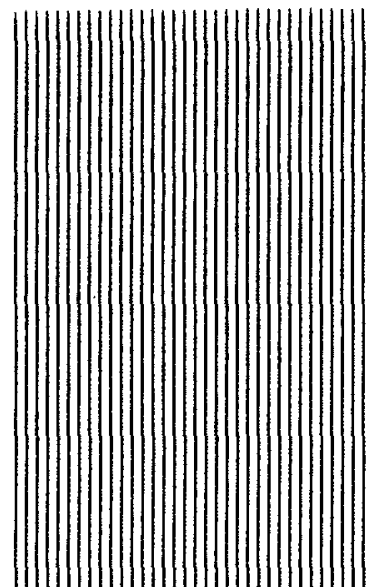

BNL- 66147

INFORMAL REPORT

\title{
ERROR REDUCTION IN DUCT LEAKAGE TESTING THROUGH DATA CROSS-CHECKS
}

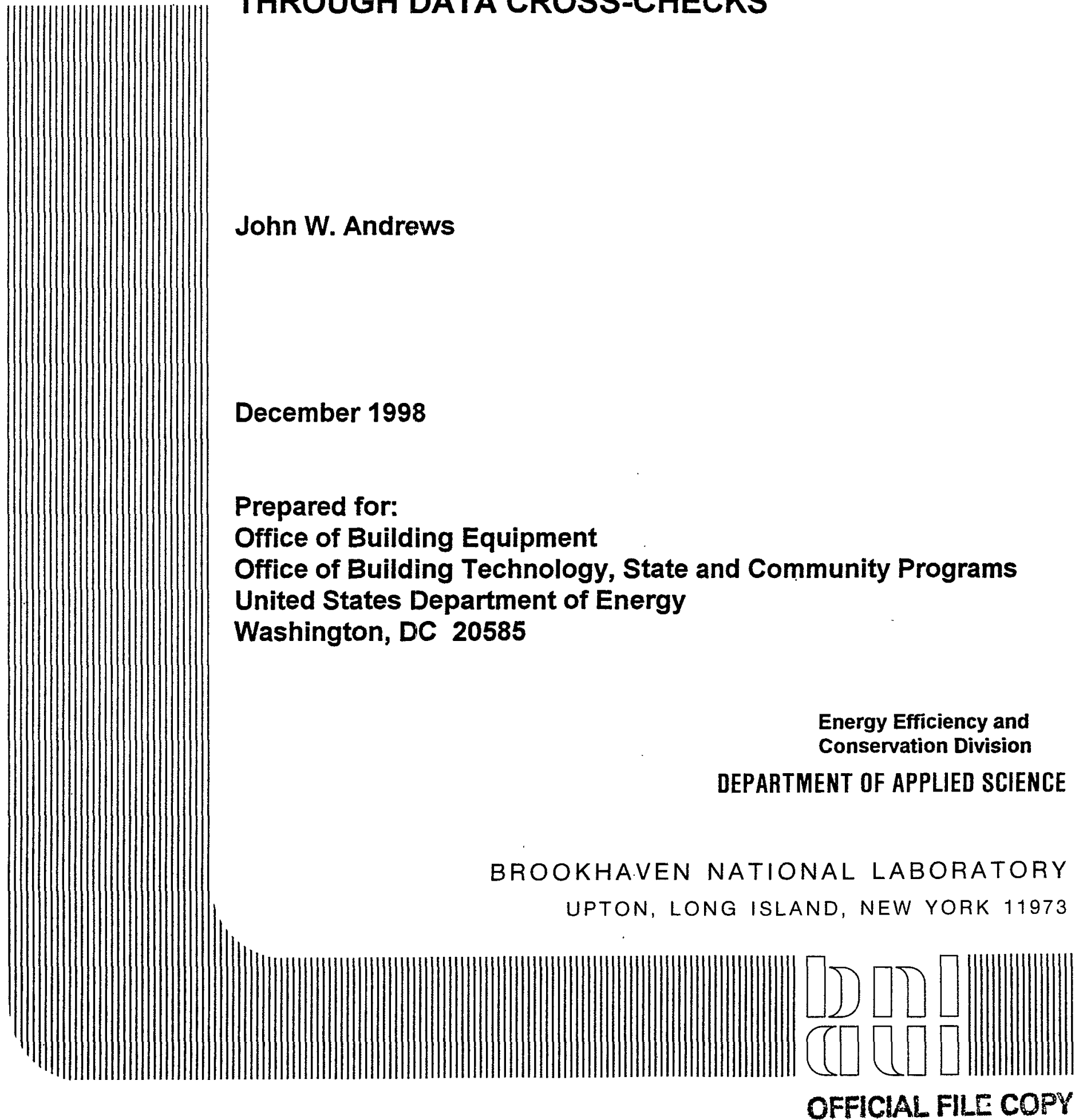




\section{DISCLAIMER}

This report was prepared as an account of work sponsored by an agency of the United States Government. Neither the United States Government nor any agency thereof, nor any of their employees, nor any of their contractors, subcontractors, or their employees makes any warranty, express or implied, or assumes any legal liability or responsibility for the accuracy, completeness, or usefulness of any information, apparatus, product or process disclosed, or represents that its use would not infringe privately owned rights. Reference herein to any specific commercial product, process, or service by trade name, trademark manufacturer, or otherwise, does not necessarily constitute or imply its endorsement, recommendation, or favoring by the United States Government or any agency thereof. The views and opinions of authors expressed herein do not necessarily state or reflect those of the United States Government or any agency, contractor, or subcontractor thereof. 
BNL- 66147

INFORMAL REPORT

\title{
ERROR REDUCTION IN DUCT LEAKAGE TESTING THROUGH DATA CROSS-CHECKS
}

BY:

JOHN W. ANDREWS

DECEMBER 1998

\begin{abstract}
Prepared for:
Office of Building Equipment

Office of Building Technology, State and Community Programs United States Department of Energy

Washington, DC 20585
\end{abstract}

Under Contract No. DE-AC02-98CH10886

Brookhaven National Laboratory

Upton, NY 11973-5000 


\begin{abstract}
One way to reduce uncertainty in scientific measurement is to devise a protocol in which more quantities are measured than are absolutely required, so that the result is "over constrained." This report develops a method for so combining data from two different tests for air leakage in residential duct systems. An algorithm, which depends on the uncertainty estimates for the measured quantities, optimizes the use of the "excess" data. In many cases it can significantly reduce the error bar on at least one of the two measured duct leakage rates (supply or return), and it provides a rational method of reconciling any conflicting results from the two leakage tests.
\end{abstract}




\section{TABLE OF CONTENTS}

Abstract $\ldots \ldots \ldots \ldots \ldots \ldots \ldots \ldots \ldots \ldots \ldots \ldots \ldots$

List of Figures $\ldots \ldots \ldots \ldots \ldots \ldots \ldots \ldots \ldots \ldots \ldots \ldots \ldots \ldots$

List of Tables $\ldots \ldots \ldots \ldots \ldots \ldots \ldots \ldots \ldots \ldots \ldots \ldots \ldots \ldots$

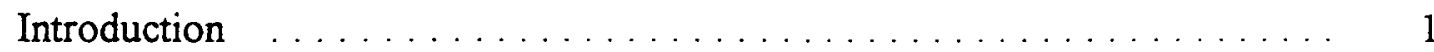

Duct Leakage Tests $\ldots \ldots \ldots \ldots \ldots \ldots \ldots \ldots \ldots \ldots \ldots \ldots$

Data Cross-Check Strategy in Duct Leakage Testing . . . . . . . . . . . . . . 2

Benchmark Cases . . . . . . . . . . . . . . . . . . . . 4

Estimating the Measurement Uncertainties. . . . . . . . . . . . . . . . . 6

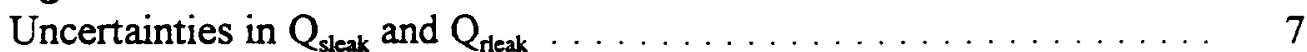

What are Typical Values for the Uncertainties in $\mathrm{Q}_{\text {sleak }}$ and $\mathrm{Q}_{\text {reak }}$ ? . . . . 8

Uncertainty in $\mathrm{Q}_{\text {sleak }+ \text { reak }} . \ldots \ldots \ldots \ldots . \ldots \ldots . \ldots \ldots$

How Large is the Uncertainty in $\mathrm{Q}_{\text {sleak+rleak }}$, and Can We

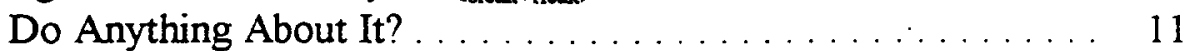

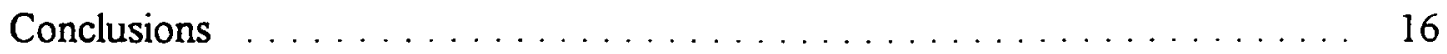

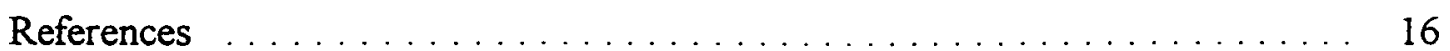

Appendix. Derivations of Equations 2 and $3 \ldots \ldots \ldots \ldots \ldots$

\section{LIST OF FIGURES}

1. Uncertainty in Supply Minus Return Leakage from Dominant

Duct Leakage Test $\left(Q_{\text {sleak +rieal }}\right)$ as Function of House Pressures . . . . . . . 15

\section{LIST OF TABLES}

1. Values of duct air leakage rate for various leakage distributions $\ldots \ldots \ldots \ldots 8$

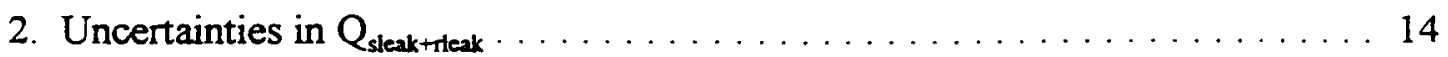

3. Number of data points required to achieve a given $95 \%$ confidence interval . . . . . . . . . . . . . . . . . . . . 14 


\section{INTRODUCTION -}

One way to reduce uncertainty in scientific measurement is to devise a protocol in which more quantities are measured than are absolutely required to calculate the desired answer. For example, if one wanted to know the volume of a vessel, one could measure its physical dimensions and calculate it that way, and then fill the vessel with water and measure the water's volume by pouring it out into a graduated cylinder. The dimensional measurements and the direct volumetric measurement would then cross-check each other, and one would expect to have greater confidence in an answer that was some kind of average of the two values for the volume than in a result that depended on only one or the other.

One problem that has to be addressed with such a strategy derives from the near certainty that the two calculated values for the desired quantity will not be exactly the same. One then has to decide how much weight to give each of them. Sometimes, instead of two completely separate values for the desired quantity, one has two test protocols whose results, when taken together, add up to more data than is strictly required, but need some disentangling to give two completely independent answers. This is the case we are going to meet in considering the data cross-check strategy in duct leakage testing.

\section{DUCT LEAKAGE TESTS}

Two duct leakage tests currently are specified as options in the draft Standard 152P, Method of Test for Determining the Design and Seasonal Efficiencies of Residential Thermal Distribution Systems, which is being developed by the American Society of Heating, Refrigerating, and AirConditioning Engineers (ASHRAE). One of these tests, called the fan pressurization test involves two steps. First, estimates for the "operating pressures" in the supply and the return duct systems are measured. The term "operating pressure" is placed in quotation marks because there is no single pressure in a working duct system. Rather, the static pressure is at a maximum (in absolute value) near the plenum and declines to near zero at the registers. The assumption of a single pressure thus is an attempt to select a likely average value representative of the system as a whole. Such an approximation will work well if the leaks are scattered throughout the duct system, but may give rise to signifficant enrors if the leaks are concentrated either at the plenum or the register boots.

The second step in the fan pressurization test is to pressurize (or depressurize) the house with a blower door (an adjustable fan calibrated to measure air flow rate as a function of throat static pressure) to some standard pressure, such as $25 \mathrm{~Pa}$. At the same time, a smaller calibrated fan (duct blower) is used to bring the pressure difference between the house and the supply or return portion of the duct system to zero. The air flow rate through the duct blower is then equal to the duct leakage rate to/from outside at the given pressure.

The final step is to pro-rate the leakage at the standard pressure to the "operating pressure" through the use of the relation $Q \propto \Delta P^{n}$, where $Q$ is the leakage flow rate, $\Delta P$ is the pressure 
difference between the inside and the outside of the duct, and $\mathrm{n}$ is an exponent that in ASHRAE Standard 152P has a default value of 0.6. The impact of uncertainty in this exponent may be minimized by using the measured "operating pressure" as the target pressure in the duct blower test, so that little or no adjustment is necessary and uncertainty in the exponent is not an issue.

An alternative duct leakage test called the house pressure test is also available within Standard 152P. In this test, the leakage flow coefficient of the house envelope is measured with a blower door, and this is then used as a standard against which the leakiness of the ducts is compared. The connection is made by means of the response of the pressure within the house (relative to the attic) when the system fan is turned on and off. If operating the system fan causes the house pressure to rise, this means that the return leakage from outside exceeds the supply leakage to outside, since a net amount of air is being taken into the duct system from outside and blown into the house. If the house pressure falls when the system fan is turned on, then the supply leakage is greater than the return leakage.

This part of the test, which is often called the dominant duct leakage test, provides a value for the signed difference between the supply and return leakage rates (i.e., an algebraic sum with supply leakage positive and return leakage negative) but it doesn't give the two values separately. To get a second equation, the house pressure test perturbs the system by partially blocking the return register(s) enough to cause a significant shift in the pressures within the return duct. With the return(s) blocked, the house pressure with the system fan on is again measured, and the extent to which this value is different from what it was with registers unblocked provides (in effect) a measure of the total supply and return leakage. Knowing the sum and the difference of the supply and return leakage rates, one can calculate them separately. The algorithm that accomplishes this task also requires values for the operating pressures in the supply and return ducts with the return register(s) unblocked and blocked.

\section{DATA CROSS-CHECK STRATEGY IN DUCT LEAKAGE TESTING}

One could imagine several alternative approaches to the data cross-check idea in duct leakage testing, but one that appears to be specially promising is the following:

1) Perform the fan pressurization test for duct leakage, giving separate values for supply leakage $\left(Q_{\text {sleak }}\right)$ and return leakage $\left(Q_{\text {rteak }}\right)$.

2) Perform the dominant duct leakage portion of the house pressure test, that is, the measurements of the house pressure with unblocked registers and system fan on and off. This provides a value for the signed difference between the supply and return leakage rates $\left(Q_{\text {sieak }+ \text { rleak }}\right)$ without requiring any pressure measurements within the ducts themselves. The second part of this suggested protocol will add very little to the total time and effort required to do the test, but provides a significant cross-check on the result, since in principle $\mathrm{Q}_{\text {sleak+rleak }}$ should equal $\mathrm{Q}_{\text {sleak }}$ $Q_{\text {rleak. }}$ However, because the actual measured values are almost certain to be inconsistent, to a greater or lesser degree, it is necessary to develop a rational method for assigning relative weights 
to the three measured quantities. Presumably this method will need to take account of the experimental uncertainties (error bars) for each of them.

Our objective is to obtain "best" values for the supply and return leakage that will use the information contained in the measured value of $Q_{\text {sleak+rleak }}$ to improve on the values of $Q_{\text {sleak }}$ and $Q_{\text {reak }}$ that were measured in the fan pressurization test. As a starting point, we note that if we define the quantities $Q_{s \text {, best }}$ and $Q_{r \text {, best }}$ to be those values for supply and return leakage that make optimal use of the available information, any candidate value for $Q_{s, b e s t}$ can be expressed in the form $a_{1} Q_{\text {sleak }}+a_{2} Q_{\text {rieak }}+a_{3} Q_{\text {sleak+rleak }}$, with the a's as coefficients to be determined. Two separate approaches to this determination have led to the same equations, which are given here. The reader who is interested in the derivation of these equations is referred to the Appendix.

As shown in the Appendix, the three coefficients can be written in terms of a single one that appears as a weighting factor, which is written as a in the equation for $Q_{s, \text { best }}$ and as $b$ in the equation for $\mathrm{Q}_{\mathrm{r}, \mathrm{best}}$ :

$$
\begin{aligned}
& Q_{\text {s, best }}=a Q_{\text {sleak }}+(1-a)\left(Q_{\text {rleak }}+Q_{\text {sleak trleak }}\right) \\
& Q_{r, \text { best }}=b Q_{\text {rleak }}+(1-b)\left(Q_{\text {sleak }}-Q_{\text {sleak }+ \text { rleak }}\right)
\end{aligned}
$$

The values of $a$ and $b$ depend on the uncertainties in the measured leakage rates, and so we need to analyze these. In dealing with experimental errors, we are considering random uncertainties only. Systematic errors are beyond the scope of the discussion, although errors due to equipment calibration are treated as random under the assumption that any given measuring device is chosen at random from an ensemble of devices with calibration errors equally likely to be positive or negative.

\begin{tabular}{|c|c|c|}
\hline $\begin{array}{l}\mathrm{mQ}_{\mathrm{s}, \text { best }} \\
\mathrm{rr} \mathrm{Q}_{\mathrm{r} \text {,best }} \\
\mathrm{rr} \mathrm{Q}_{\mathrm{r}}\end{array}$ & $\begin{array}{l}= \\
= \\
= \\
=\end{array}$ & $\begin{array}{l}\text { Random uncertainty in } Q_{\text {s,best }} \\
\text { Random uncertainty in } Q_{r \text {,best }} \\
\text { Random uncertainty in } Q_{\text {steak }} \\
\text { Random uncertainty in } Q_{\text {rleak }} \\
\text { Random uncertainty in } Q_{\text {sleak +rleal }}\end{array}$ \\
\hline
\end{tabular}

Let us define the experimental uncertainties as follows:

The analysis in the Appendix then yields the following equations for $a$ and $b$ : 


$$
\begin{aligned}
& a=\frac{\left(e r r Q_{r}\right)^{2}+\left(e r r Q_{s r}\right)^{2}}{\left(e r r Q_{s}\right)^{2}+\left(e r r Q_{r}\right)^{2}+\left(e r r Q_{s r}\right)^{2}} \\
& b=\frac{\left(e r r Q_{s}\right)^{2}+\left(e r r Q_{s r}\right)^{2}}{\left(e r r Q_{s}\right)^{2}+\left(e r r Q_{r}\right)^{2}+\left(e r r Q_{s r}\right)^{2}}
\end{aligned}
$$

Further analysis yields remarkably simple formulas for the uncertainties in $Q_{s, b e s t}$ and $Q_{r, b e s t}$ :

$$
\begin{aligned}
& e r r Q_{s, b e s t}=\sqrt{a} \mathrm{err} Q_{s} \\
& e r r Q_{r \text { best }}=\sqrt{b} \mathrm{err} Q_{r}
\end{aligned}
$$

We first note that from Equations 2 it is obvious that $\mathrm{a}$ and $\mathrm{b}$ are between 0 and 1 , and hence the uncertainties in $\mathrm{Q}_{\mathrm{s}, \text { best }}$ and $\mathrm{Q}_{\mathrm{r} \text {,best }}$ will always be less than the corresponding uncertainties in $\mathrm{Q}_{\text {sleak }}$ and $\mathrm{Q}_{\text {rleak }}$. This is to be expected, given the additional information provided by $\mathrm{Q}_{\text {sleak+rieak }}$.

\section{BENCHMARK CASES}

To show what the data cross-check strategy can do to reduce uncertainties and reconcile data, let us consider four benchmark cases, two with balanced duct leakage and two with unbalanced leakage. We will assume in each case that the uncertainties in $\mathrm{Q}_{\text {seak }}$ and $\mathrm{Q}_{\text {reak }}$ are each $30 \%$ of their measured values, and that the uncertainty in $\mathrm{Q}_{\text {sleak }+ \text { teak }}$ is $\pm 30 \mathrm{cfm}$. (These values are within the range of estimates developed below.) For each of these categories, we'll examine what the procedure does when the values are quite compatible with one another, and what happens when they are significantly at variance. It is assumed that all the uncertainties are given at the same level of confidence (e.g., 95\%).

Case 1. Balanced Leakage. Compatible Values. Here we'll assume:

- $\mathrm{Q}_{\text {sleak }}=100 \pm 30 \mathrm{cfm}$
- $\quad \mathrm{Q}_{\text {rleak }}=100 \pm 30 \mathrm{cfm}$
$\mathrm{Q}_{\text {sleak+rileak }}=0 \pm 30 \mathrm{cfm}$

Equation 2 yields $a=0.67$ and $b=0.67$ and these values in Equation 1 yield $Q_{s, b e s t}=100 \mathrm{cfm}$ and $\mathrm{Q}_{\mathrm{r}, \text { best }}=100 \mathrm{cfm}$. The best values of supply and return leakage are no different from the original 
ones because the three inputs are compatible. The error bars, however, have shrunk a bit by virtue of Equation 4, by the factor of $\sqrt{ } 0.67$, so that:

$$
\mathrm{Q}_{\mathrm{s}, \text { best }}=100 \pm 25 \mathrm{cfm} \quad \mathrm{Q}_{\mathrm{r}, \text { best }}=100 \pm 25 \mathrm{cfm} .
$$

The main benefit here is not a great reduction in the error bars (though there is some reduction) but a confirmation that the leakage values as measured by fan pressurization are probably quite good.

Case 2. Balanced Leakage, Incompatible Values. Here we'll assume:

$$
\begin{array}{ll}
\text { - } & \mathrm{Q}_{\text {sleak }}=100 \pm 30 \mathrm{cfm} \\
\text { - } & \mathrm{Q}_{\text {reak }}=100 \pm 30 \mathrm{cfm} \\
\mathrm{Q}_{\text {sleak }+ \text { rleak }}=100 \pm 30 \mathrm{cfm}
\end{array}
$$

These are incompatible because the measured values of supply and return leakage are the same, yet the dominant duct leakage test gives a value significantly different from zero. Since the error bars are the same as before, Equation 3 again yields $a=0.67$ and $b=0.67$. Equation 1, however, is different, yielding $Q_{s, b e s t}=133 \mathrm{cfm}$ and $Q_{r, b e s t}=67 \mathrm{cfm}$. The error bars are the same as in the previous case (since $a, b$, and the original error bars are the same), so that now

$$
\mathrm{Q}_{\mathrm{s}, \text { best }}=133 \pm 25 \mathrm{cfm} \quad \mathrm{Q}_{\mathrm{r}, \text { best }}=67 \pm 25 \mathrm{cfm} .
$$

This seems like a fairly good compromise among the original data, with $Q_{s, b e s t,} Q_{r, b e s t r}$ and $\mathrm{Q}_{\mathrm{s}, \text { best }}-\mathrm{Q}_{\mathrm{r}, \text { best }}$ being about one error bar away from the original $\mathrm{Q}_{\text {sleak, }}, \mathrm{Q}_{\mathrm{rleak}}$, and $\mathrm{Q}_{\text {sleak+rleak, }}$ respectively. These values probably represent a closer approximation to the truth of what is going on than the original $Q_{\text {steak }}$ and $Q_{\text {rleak }}$.

Case 3. Unbalanced Leakage, Compatible Values. Here we'll assume:

$$
\begin{array}{ll}
- & \mathrm{Q}_{\text {steak }}=100 \pm 30 \mathrm{cfm} \\
- & \mathrm{Q}_{\text {rieak }}=200 \pm 60 \mathrm{cfm} \\
& \mathrm{Q}_{\text {steak +rleak }}=-100 \pm 30 \mathrm{cfm}
\end{array}
$$

Equation 3 yields $a=0.83$ and $b=0.33$. Equation 1 then gives $Q_{s, b e s t}=100 \mathrm{cfm}$ and $Q_{x, \text { best }}=$ $200 \mathrm{cfm}$. The equality of the "best" values with the original values of supply and return leakage is not surprising since $\mathrm{Q}_{\text {sleak }+ \text { iceak }}$ is consistent with them. The fact that $\mathrm{Q}_{\text {steak+rleak }}$ has been measured reduces the error on the return side by the factor $\sqrt{ } 0.33$, from $60 \mathrm{cfm}$ to $34 \mathrm{cfm}$. The supply leakage error is affected very little since $a$ is so close to unity. So our "best" values with errors are:

$$
\mathrm{Q}_{\mathrm{s}, \text { best }}=100 \pm 27 \mathrm{cfm} \quad \mathrm{Q}_{\mathrm{r}, \text { best }}=200 \pm 34 \mathrm{cfm} .
$$


The benefit here is confirmation of the leakage values as measured by fan pressurization, coupled with a reduced error bar on the return leakage.

Case 4. Unbalanced Leakage, Incompatible Values. It is not uncommon for the dominant duct leakage test and the fan pressurization test to disagree on whether supply or return leakage is greater. Here is an example:

- $\mathrm{Q}_{\text {sleak }}=100 \pm 30 \mathrm{cfm}$

- $\mathrm{Q}_{\text {reak }}=200 \pm 60 \mathrm{cfm}$

- $\mathrm{Q}_{\text {sleak }+ \text { reak }}=50 \pm 30 \mathrm{cfm}$

Fan pressurization indicates greater return leakage than supply leakage, while the dominant duct leakage test says the opposite. How is this resolved? Equation 2 yields $a=0.83$ and $b=0.33$. Equation 1 then gives $Q_{s, b e s t}=126 \mathrm{cfm}$ and $Q_{r, b e s t}=100 \mathrm{cfm}$. The procedure weighs the uncertainties in the measured quantities to see which it "believes" more than the others. In this case, the larger uncertainty in the measured return leakage weighs against it, and the compromise result has the system supply-dominant. Our "best" values with errors are:

$$
\mathrm{Q}_{\mathrm{s}, \text { best }}=126 \pm 27 \mathrm{cfm} \quad \mathrm{Q}_{\mathrm{r}, \text { best }}=100 \pm 34 \mathrm{cfm} .
$$

Note that $Q_{s, b e s t}-Q_{r, b e s t}=26 \pm 43 \mathrm{cfm}$ (combining the two error bars by quadrature addition) so the system could be balanced or even slightly return-dominant consistent with the "best" results obtained here. The benefit here is a best compromise between divergent results from the two test methods that does the least violence to any of the data.

These examples (especially Case 3 and Case 4) show how the inclusion of the dominant duct leakage test can reduce the uncertainty in the duct leakage values. Critical to the project is a reasonably accurate assessment of the relative uncertainties in the individual measurements. In Case 4, for example, one would suspect that the error estimate for either the return leakage measurement by fan pressurization or the dominant duct leakage test might be too low. On the other hand, errors are random and once in a while one expects to be outside even a $95 \%$ confidence limit. The fact that the individual leakage measurements (via fan pressurization) often give the opposite sign on the dominant duct leakage to that obtained using the fan-on and fan-off house pressures should motivate the use of a test that includes all of this information.

\section{ESTIMATING THE MEASUREMENT UNCERTAINTIES}

The above analysis differs from previous duct leakage tests in that the result depends on estimates of the measurement uncertainties for the three input quantities $\mathrm{Q}_{\text {sleak, }} \mathrm{Q}_{\text {reakk, }}$ and $\mathrm{Q}_{\text {sleak }+ \text { tleak. }}$. It's therefore important to consider how these uncertainties should be estimated in terms of the measured quantities from which they are calculated. 


\section{Uncertainties in Osleak and Qrleak}

The simplest analysis of errors in the fan pressurization test would be that for a one-point test, in which a duct leakage flow coefficient ( $C$ in the expression $C \Delta P^{n}$ ) is determined at some pressure $\mathrm{A}$, and then this leakage is corrected to the assumed operating pressure $\mathrm{p}$ using a standard value for $\mathrm{n}$, such as 0.6 . This has been criticized on the basis of the likelihood that if $\mathrm{A}$ and $\mathrm{p}$ are different, significant error can arise from choosing the wrong value of $n$. As discussed above, however, if the pressure $p$ is determined before the duct blower test is done, then it should be possible to pressurize the duct to this level (unless the operating pressure exceeds what the duct blower can attain). If the operating pressure can be attained by the duct blower, then the effect of an error in $n$ will be essentially zero, because little or no pro-rating will be necessary.

What would the errors look like in this case? Again using the basic equation $Q=C p^{n}$, we measure $Q_{A}$ at some pressure $A$ that is close enough to $p$ that uncertainty in $n$ can be ignored. We can then rewrite the basic equation as $Q=Q_{A} p^{n} / A^{n}$, where $Q$ stands for either $Q_{\text {sleak }}$ or $Q_{\text {rleaks }}$, depending on which side of the duct system is being tested. The total differential of $\mathrm{Q}$ is then:

$$
\begin{aligned}
d Q & =\frac{\partial Q}{\partial Q_{A}} d Q_{A}+\frac{\partial Q}{\partial p} d p \\
& =\frac{p^{n}}{A^{n}} d Q_{A}+n Q_{A} \frac{p^{n-1}}{A^{n}}
\end{aligned}
$$

This leads to:

$$
\frac{d Q}{Q}=\frac{d Q_{A}}{Q_{A}}+n \frac{d p}{p}
$$

and using the same conventions as before, we may write:

$$
\frac{e r r Q}{Q}=\sqrt{\left(\frac{e r r Q_{A}}{Q_{A}}\right)^{2}+n^{2}\left(\frac{e r r p}{p}\right)^{2}}
$$

where $\operatorname{err} Q_{A} / Q_{A}$ is the fractional error in the measured leakage rate at pressure $A$ and err $p / p$ is the fractional error in the operating pressure. 


\section{What are Typical Values for the Uncertainties in Osleak and Orleak?}

A strong argument can be made that in most cases the second term under the square root in Equation 6 will greatly exceed the first term. Table 1 gives values of the duct leakage rate for various assumptions about the distribution of leaks, as percentages of the leakage rate if all the leaks are at the plenum, with $\mathrm{n}=0.6$ and boot static pressure $15 \%$ of that at the plenum.

The range of uncertainty implied by this table may be underestimated. Some researchers have reported that static pressures at supply boots may under some circumstances actually be negative (due to Bernoulli effect), in which case supply leakage could in principle be into the duct!

For these reasons, we suggest that a reasonable benchmark for a one-standard-deviation error on the duct operating pressure would include categories 3 through 6 in Table 1 , for a $\pm 25 \%$ error bar, while a $95 \%$ confidence interval would include all the values listed above, which would imply $\sim 50 \%$ error bar surrounding a central value represented by taking the operating pressure to be half that at the plenum.

Table 1. Values of duct air leakage rate for various leakage distributions in a duct, as percentages of the leakage when all the leakage is at the plenum. (Boot pressure $=0.15$ plenum pressure.)

\begin{tabular}{|l|l|}
\hline Leakage Distribution & Duct Leakage Rate (\% of Benchmark) \\
\hline 1. All leaks at plenum (benchmark case) & 100 \\
\hline 2. $90 \%$ of leaks at plenum, $10 \%$ at boots & 93 \\
\hline 3. $75 \%$ of leaks at plenum, $25 \%$ at boots & 83 \\
\hline 4. $50 \%$ of leaks at plenum, $50 \%$ at boots & 66 \\
\hline $\begin{array}{l}\text { 5. All leaks at a point where pressure is one- } \\
\text { half plenum pressure }\end{array}$ & 66 \\
\hline 6. $25 \%$ of leaks at plenum, $75 \%$ at boots & 49 \\
\hline 7. $10 \%$ of leaks at plenum, $90 \%$ at boots & 39 \\
\hline 8. All leaks at boots & 32 \\
\hline
\end{tabular}

An estimated range for a $95 \%$ confidence interval on the duct leakage measurement (errQ $Q_{A} / Q_{A}$ ) is suggested as 0.10 to 0.25 depending on the type of duct (simple, tight ducts would have uncertainty in the low end of the range, while complex, leaky ducts could be at the high end or higher). A fractional uncertainty of 0.15 is suggested as a benchmark.

These values are provisional but are believed by the author to be reasonable estimates for a typical case. The use of data cross-checking methods by researchers in the future can help to elucidate the general question of error magnitudes. 
Using these estimates provides the following overall error estimate on $\mathrm{Q}_{\text {sleak }}$ or $\mathrm{Q}_{\text {reak: }}$ :

$$
\begin{aligned}
\frac{e r r Q}{Q} & =\sqrt{0.15^{2}+(0.6)^{2}(0.5)^{2}} \\
& =\sqrt{0.022+0.090} \\
& =0.33
\end{aligned}
$$

If the first term is ignored, the result would be 0.30 , not a large difference. Hence the judgment that the second term usually dominates.

\section{Uncertainty in Osleak+rleak}

The expression for the error in $\mathrm{Q}_{\text {steak }+ \text { treak }}$ is somewhat more complicated. It is a function of four measured variables, $\Delta \mathrm{P}_{\text {on }}, \Delta \mathrm{P}_{\text {off }}$ and $\mathrm{C}_{\text {env }}$ and $\mathrm{n}_{\text {env }}$, defined as follows:

$\Delta \mathrm{P}_{\text {on }} \quad$ Pressure difference between house and attic with the system fan on $\Delta \mathrm{P}_{\text {off }}$ Pressure difference between house and attic with the system fan off

$\mathrm{C}_{\mathrm{env}}$ Envelope flow coefficient as determined by a blower door test with sealed registers

$\mathrm{n}_{\mathrm{env}}$ Envelope flow exponent

The expression for $\mathrm{Q}_{\text {sleakt+leak }}$ in ASHRAE Standard 152P is:

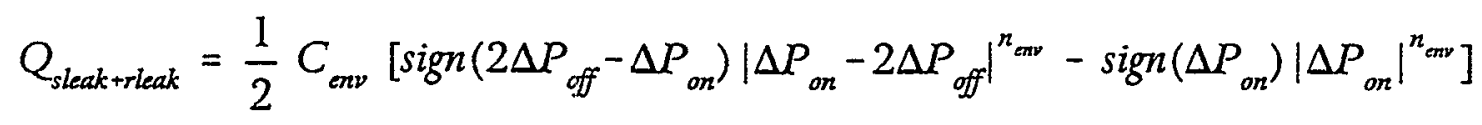

In what follows we will assume that the blower door test was a multi point test, so that the exponent $n_{e n v}$ is well defined and most of the measurement error on envelope leakage is embodied in uncertainty in $\mathrm{C}_{\text {env. }}$. In this case, the total differential of $\mathrm{Q}_{\text {steak reak }}$ can be written as follows:

$$
d Q_{\text {sleak }+r \text { leak }}=\frac{\partial Q_{\text {sleak }+ \text { reak }}}{\partial C_{e n v}} d C_{c n \nu}+\frac{\partial Q_{\text {sleak }+ \text { rleak }}}{\partial \Delta P_{\text {on }}} d \Delta P_{\text {on }}+\frac{\partial Q_{\text {sleak }+r \text { leak }}}{\partial \Delta P_{\text {off }}} d \Delta P_{\text {off }}
$$

The partial derivatives of $Q_{\text {sleak }+ \text { reak }}$ with respect to the three independent variables are: 


$$
\begin{aligned}
& \frac{\partial Q_{\text {sleak }+ \text { rleak }}}{\partial \Delta P_{o n}}=-\frac{1}{2} C_{e n v} n_{e n \nu}\left[\left|2 \Delta P_{o f f}-\Delta P_{o n}\right|^{n_{e n v}-1}+\left|\Delta P_{o n}\right|^{n_{c n v}-1}\right] \\
& \frac{\partial Q_{\text {sleak }+r \text { leak }}}{\partial \Delta P_{\text {off }}}=C_{e n \nu} n_{e n v}\left[\left|2 \Delta P_{\text {off }}-\Delta P_{o n}\right|^{n_{\text {onv }}-1}\right. \\
& \frac{\partial Q_{\text {sleak }+r \text { leak }}}{\partial C_{e n v}}=\frac{Q_{s r}}{C_{e n v}}
\end{aligned}
$$

Because these expressions are somewhat unwieldy, it may prove useful to give functional names to the expressions in $\Delta \mathrm{P}_{\text {on }}$ and $\Delta \mathrm{P}_{\text {off }}$ :

$$
\begin{aligned}
& f=\left|2 \Delta P_{o f f}-\Delta P_{o n}\right|^{n_{e m v}-1}+\left|\Delta P_{o n}\right|^{n_{m v}-1} \\
& g=\left|2 \Delta P_{o f f}-\Delta P_{o n}\right|^{n_{e n v}-1}
\end{aligned}
$$

The function $f$ is the same as that defined in a previous error analysis of the house pressure test.[Andrews 1997], and $g$ is related to the functions $g_{R}$ and $g_{S}$ defined in the same report, but lacks elements relating to supply and return duct pressures and blocked-return house pressures, none of which pertain to the unblocked-register portion of the house pressure test.

The next step is to take the differentials in Equation 8 as uncorrelated deviations from true values, and introduce the following nomenclature similar in character to that previously defined:

$$
\begin{array}{lll}
\text { err } \Delta \mathrm{P}_{\text {on }} & = & \text { random uncertainty in the fan-on house pressure } \\
\mathrm{err} \Delta \mathrm{P}_{\text {off }} & = & \text { random uncertainty in the fan-off house pressure } \\
\mathrm{err} \mathrm{C}_{\text {env }} & = & \text { random uncertainty in the envelope flow coefficient }
\end{array}
$$

The uncertainties in the independent variables can then be added in quadrature to obtain:

$$
e r r Q_{s r}=\left[\left(\frac{C_{e n \nu} n_{e n v} f}{2}\right)^{2}\left(e r r \Delta P_{o n}\right)^{2}+\left(C_{e n v} n_{e n v} g\right)^{2}\left(e r r \Delta P_{o f f}\right)^{2}+\left(\frac{Q_{s r}}{C_{e n v}}\right)^{2}\left(e r r C_{e n v}\right)^{2}\right]^{1 / 2}
$$

A final step in defining the error in $\mathrm{Q}_{\text {sleak }}$ treak requires us to go beyond Equation 7 to consider possible uncertainties caused by lack of knowledge of the distribution of leakage area within the building envelope. This possibility is not embedded in Equation 7 because that equation is based 
on a particular assumption concerning this distribution, namely that the leakage area is equally split between the floor and the ceiling, with none assigned to the walls. In another report by the author [Andrews 1998] these assumptions have been generalized to allow an arbitrary distribution of the leakage area, and the degree to which this introduces uncertainty in $\mathrm{Q}_{\text {sleak+rleak }}$ has been investigated. In general, it has been found that agreement between the generalized equation and Equation 7 is usually good to within $\pm 5 \%$, but that deviations of $50 \%$ or more can occasionally occur. Three "danger signals" were identified that should generate suspicion--but not necessarily confirm--the presence of a large uncertainty in $\mathrm{Q}_{\text {sleak+rleak }}$ caused by uncertainty in the envelope leakage distribution. These danger signals are:

$\begin{array}{ll}- & \left|\Delta \mathrm{P}_{\text {off }}\right| \text { "large" } \\ - & \left|\Delta \mathrm{P}_{\text {on }}\right| \text { "small" } \\ - & \Delta \mathrm{P}_{\text {off }} \approx 0.5 \Delta \mathrm{P}_{\text {on }}\end{array}$

These criteria may seem annoyingly vague, and it is hoped that they can soon be made more precise. Tentatively, it is ventured that "large" in the first danger sign means, roughly, $>1 \mathrm{~Pa}$; "small" in the second danger sign means, roughly, $<0.5 \mathrm{~Pa}$; and "approximately equal to half" in the third danger sign means, roughly, between one-fourth and three-fourths. The first danger sign stems from the fact that when $\Delta \mathrm{P}_{\text {off }}=0$, it doesn't matter what the distribution of envelope leakage is; it's only when this quantity is significant that the response of the envelope can depend on where the leakage is. The second and third danger signs appear to emanate from a particular sensitivity of the equations to changes in the variables whenever the pressure difference across the ceiling or the floor is near zero when the system fan is on.

At this point, we will introduce a term err $\mathrm{Q}_{\mathrm{Ikdist}}$ to denote the uncertainty in $\mathrm{Q}_{\text {sleak+rleak }}$ caused by uncertainty in the distribution of leakage area over the building envelope. As this error is unlikely to be correlated with any of the terms within Equation 11, it will be added on in quadrature:

$$
\begin{aligned}
e r r Q_{s r}= & {\left[\left(\frac{C_{e n v} n_{e n v} f}{2}\right)^{2}\left(e r r \Delta P_{o n}\right)^{2}+\left(C_{e n v} n_{e n v} g\right)^{2}\left(e r r \Delta P_{o f f}\right)^{2}+\right.} \\
& \left.+\left(\frac{Q_{s r}}{C_{e n v}}\right)^{2}\left(e r r C_{e n v}\right)^{2}+\left(e r r Q_{l k d i s t}\right)^{2}\right]^{1 / 2}
\end{aligned}
$$

\section{How Large Is the Uncertainty in Osleak+rleak, and Can We Do Anything About It?}

It would be useful to be able to assess typical relative magnitudes of the four terms within the square root on the right-hand-side of Equation 12. It is also useful to know that the experimenter has some control over the first two terms. By measuring $\Delta \mathrm{P}_{\text {on }}$ and $\Delta \mathrm{P}_{\text {off }}$ many times, it is in principle possible to reduce these terms to arbitrarily small values. The number of measurements 
required to reduce them below a certain point, however, is likely to become prohibitive in time, effort, and value in reducing the overall uncertainty in $\mathrm{Q}_{\text {sleak }+ \text { rleak. }}$

In estimating these first two terms, a value for $\mathrm{n}_{\text {env }}$ of 0.65 can be used, since this exponent is usually found to lie within $15 \%$ of that value. The function $f$ is usually found [Andrews 1977] to lie between 1 and $3 \mathrm{~Pa}^{-0.35}$. The $\mathrm{g}$ function is similar to $\mathrm{f}$ but has only one term instead of two additive ones, and so can be expected, on average, to be about half as large as $f$. These functions can be evaluated for any particular case, and a spreadsheet could calculate them effortlessly. For discussion here, however, we will use $\mathrm{f} \approx 2$ and $\mathrm{g} \approx 1$ when discussing likely error magnitudes.

The uncertainties in $\Delta \mathrm{P}_{\text {on }}$ and $\Delta \mathrm{P}_{\text {off }}$ are to some extent controlled by nature (with gusty winds in particular tending to drive these up) but, as mentioned above, they are also partly under the control of the tester, by virtue of the ability to make additional measurements. The uncertainty in these values is roughly halved for every fourfold increase in the number of data points.

Considering the third term, manufacturers of blower doors generally quote a $5 \%$ margin of calibration error. Given that any operator error would add to this, it would seem prudent to assign $\mathrm{a} \sim 10 \%$ uncertainty to the measurement of $\mathrm{C}_{\mathrm{env}}$.

As for the err $\mathrm{Q}_{\mathrm{kkdist}}$ term, on the basis of the above discussion it appears that when the "danger signs" are not present, one can depend on Equation 7 to be accurate within $5 \%$. When one or more of those signs is present, an analysis can be done using the equations in Andrews 1998. Failing that, and as a benchmark here, a default value of $0.3 \mathrm{Q}_{\text {sleak+rieak }}$ will be used.

This means that when the danger signs are absent, uncertainty in $\mathrm{C}_{\mathrm{env}}$ will overshadow that caused by uncertainty in the leakage distribution, but when they are present, the leakage distribution uncertainty will dominate. Taking the two terms together, then, one might assign a combined fractional uncertainty of $\sim 10 \%$ to the two causes together (10\% and $5 \%$ added in quadrature, one significant figure in the answer) when the danger signs are absent, and $-30 \%(10 \%$ and $30 \%$ added in quadrature) when they are present. Finally, to aid our conceptual thinking about this equation, we'll convert $\mathrm{C}_{\text {env }}$ to CFM50 using the relation CFM50 $=50^{.65} \mathrm{C}_{\mathrm{env}}$

These considerations lead to the following "rule of thumb" equations:

$$
e r r Q_{s r}=\left\{(0.05 C F M 50)^{2}\left[\left(e r r \Delta P_{\text {on }}\right)^{2}+\left(e r r \Delta P_{\text {off }}\right)^{2}\right]+\left(0.1 Q_{s r}\right)^{2}\right\}^{1 / 2}
$$

if the "danger signs" of uncertainty due to envelope leakage distribution are absent, and

$$
e r r Q_{s r}=\left\{(0.05 C F M 50)^{2}\left[\left(e r r \Delta P_{o n}\right)^{2}+\left(e r r \Delta P_{o f f}\right)^{2}\right]+\left(0.3 Q_{s r}\right)^{2}\right\}^{1 / 2}
$$

if one or more of the "danger signs" is present. 
In order to gain some insight into the expected size of err $\mathrm{Q}_{s \mathrm{r}}$ we'll look at the results for a number of values of CFM50, $\mathrm{Q}_{\text {sleak+rleak, }}$ err $\Delta \mathrm{P}_{\text {on }}$ and err $\Delta \mathrm{P}_{\text {off }}$ :

- $\quad$ CFM50 $=2000$ and 4000 (representing reasonably tight and leaky housing, respectively)

- $\mathrm{Q}_{\mathrm{sr}}=200,100,50$, and 0 (representing a range of non-negative values; negative values of $\mathrm{Q}_{\mathrm{sr}}$ will behave similarly)

- $\quad \operatorname{err} \Delta \mathrm{P}_{\text {on }}=\operatorname{err} \Delta \mathrm{P}_{\text {off }}$ with values $0.5,0.4,0.3,0.2$, and $0.1 \mathrm{~Pa}$.

Table 2 shows values of errQ $\mathrm{s}_{\mathrm{sr}}$ for all combinations of the above values, for both levels of uncertainty due to envelope leakage distribution embodied in Equations 13a and 13b. The impact of this uncertainty is most significant when $\mathrm{Q}_{\text {sleaktrleak }}$ has values far from zero and the uncertainties in $\Delta \mathrm{P}_{\text {on }}$ and $\Delta \mathrm{P}_{\text {off }}$ are lowest. Wherl $\mathrm{Q}_{\text {sleaktrleak }}$ is near zero or when the uncertainties in $\Delta \mathrm{P}_{\text {on }}$ and $\Delta \mathrm{P}_{\text {off }}$ are high, the uncertainty in $\mathrm{Q}_{\text {sleak }+ \text { treak }}$ is quite insensitive to the envelope leakage distribution because that uncertainty is either low (in the case of small $Q_{\text {steak }+ \text { ileak }}$ ) or it is overshadowed by other factors.

Figure 1 summarizes these results. Two families of curves are shown, one for CFM50 $=2000$ and the other for CFM50 $=4000$. Within each family are three curves, an upper one and two closetogether lower ones. The upper curve represents a case of fairly high $\mathrm{Q}_{\text {steak }+ \text { reak }}$ coupled with high uncertainty in this parameter due to uncertainty in the distribution of leakage area in the building envelope. The two lower curves show that if the uncertainty due to envelope leakage distribution is low, then the uncertainty in $\mathrm{Q}_{\text {sleak+rileak }}$ is not a strong function of $\mathrm{Q}_{\text {sleak }+ \text { rleak }}$ itself.

A question the reader might ask is, "How low can the uncertainty in the house pressures be?" In principle, this can be brought to as low a level as one wants simply by taking enough values, but beyond a certain point this becomes prohibitively time-consuming.

The number of data points needed to achieve a given level of uncertainty in $\Delta \mathrm{P}_{\text {on }}$ or $\Delta \mathrm{P}_{\text {off }}$ will depend on the level of confidence in the uncertainty interval and the variability of the data (expressed as a standard deviation). In general, the half-width of an error bar at the level of confidence $1-\alpha$ is given by $t_{\alpha / 2} s / V n$, where $n$ is the number of data points, $s$ is the sample standard deviation of the data, and $t_{\alpha / 2}$ is the value of the $t$ distribution with $n-1$ degrees of freedom, leaving an area $\alpha / 2$ to the right. Table 3 shows the number of data points required, using this formula, for various standard deviations of data and required $95 \%$ confidence intervals for $\Delta \mathrm{P}_{\text {on }}$ or $\Delta \mathrm{P}_{\text {off }}$. 
Table 2. Uncertainties in $\mathrm{Q}_{\text {sieak+rieak }}$ as a function of envelope leakage (CFM50), the value of Qsleak+rleak, and the uncertainties in the house pressures $\Delta \mathrm{P}_{0 \mathrm{p}}$ and $\Delta \mathrm{P}_{\text {off. }}$

\begin{tabular}{|c|c|c|c|c|c|}
\hline \multirow{2}{*}{$\begin{array}{c}\mathrm{Q}_{\text {sleak }+ \text { rieak }}, \\
\mathrm{cfm}\end{array}$} & \multirow{2}{*}{$\begin{array}{l}\text { err } \Delta P_{\text {on }} \text { and } \\
\text { err } \Delta P_{\text {off }} \\
\quad \mathrm{Pa}\end{array}$} & \multicolumn{2}{|c|}{$\begin{array}{l}\text { errQ } \\
\text { envelope leakage distribution), cfm }\end{array}$} & \multicolumn{2}{|c|}{$\begin{array}{l}\text { errQ } \\
\text { envelope leakh uncertainty from } \\
\text { enstribution), } \mathrm{cfm}\end{array}$} \\
\hline & & CFM50 $=2000$ & CFM50 $=4000$ & CFM50 $=2000$ & CFM $50=4000$ \\
\hline 200 & 0.5 & 73 & 143 & 93 & 154 \\
\hline 200 & 0.4 & 60 & 115 & 82 & 128 \\
\hline 200 & 0.3 & 47 & 87 & 73 & 104 \\
\hline 200 & 0.2 & 35 & 60 & 66 & 82 \\
\hline 200 & 0.1 & 24 & 35 & 62 & 66 \\
\hline 100 & 0.5 & 71 & 142 & 77 & 145 \\
\hline 100 & 0.4 & 57 & 114 & 64 & 117 \\
\hline 100 & 0.3 & 44 & 85 & 52 & 90 \\
\hline 100 & 0.2 & 30 & 57 & 41 & 64 \\
\hline 100 & 0.1 & 17 & 30 & 33 & 41 \\
\hline 0 & 0.5 & 71 & 141 & 71 & 141 \\
\hline 0 & 0.4 & 57 & 113 & 57 & 113 \\
\hline 0 & 0.3 & 42 & 85 & 42 & 85 \\
\hline 0 & 0.2 & 28 & 57 & 28 & 57 \\
\hline 0 & 0.1 & 14 & 28 & 14 & 28 \\
\hline
\end{tabular}

Table 3. Number of data points required to achieve a given $95 \%$ confidence interval, for various sample standard deviations of data and required error intervals for $\Delta \mathrm{P}_{\text {on }}$ or $\Delta \mathrm{P}_{\text {off }}$.

\begin{tabular}{|c|c|c|c|c|}
\hline $\begin{array}{c}\text { Sample Standard Deviation, } \mathrm{Pa} \\
\text { Required 95\% Confidence Interval, } \mathrm{Pa}\end{array}$ & 0.3 & 0.5 & 0.7 & 1.0 \\
\hline 0.5 & 4 & 7 & 10 & 18 \\
\hline 0.4 & 5 & 9 & 15 & 27 \\
\hline 0.3 & 7 & 14 & 24 & 45 \\
\hline 0.2 & 12 & 27 & 50 & 95 \\
\hline 0.1 & 35 & 100 & 190 & 390 \\
\hline
\end{tabular}




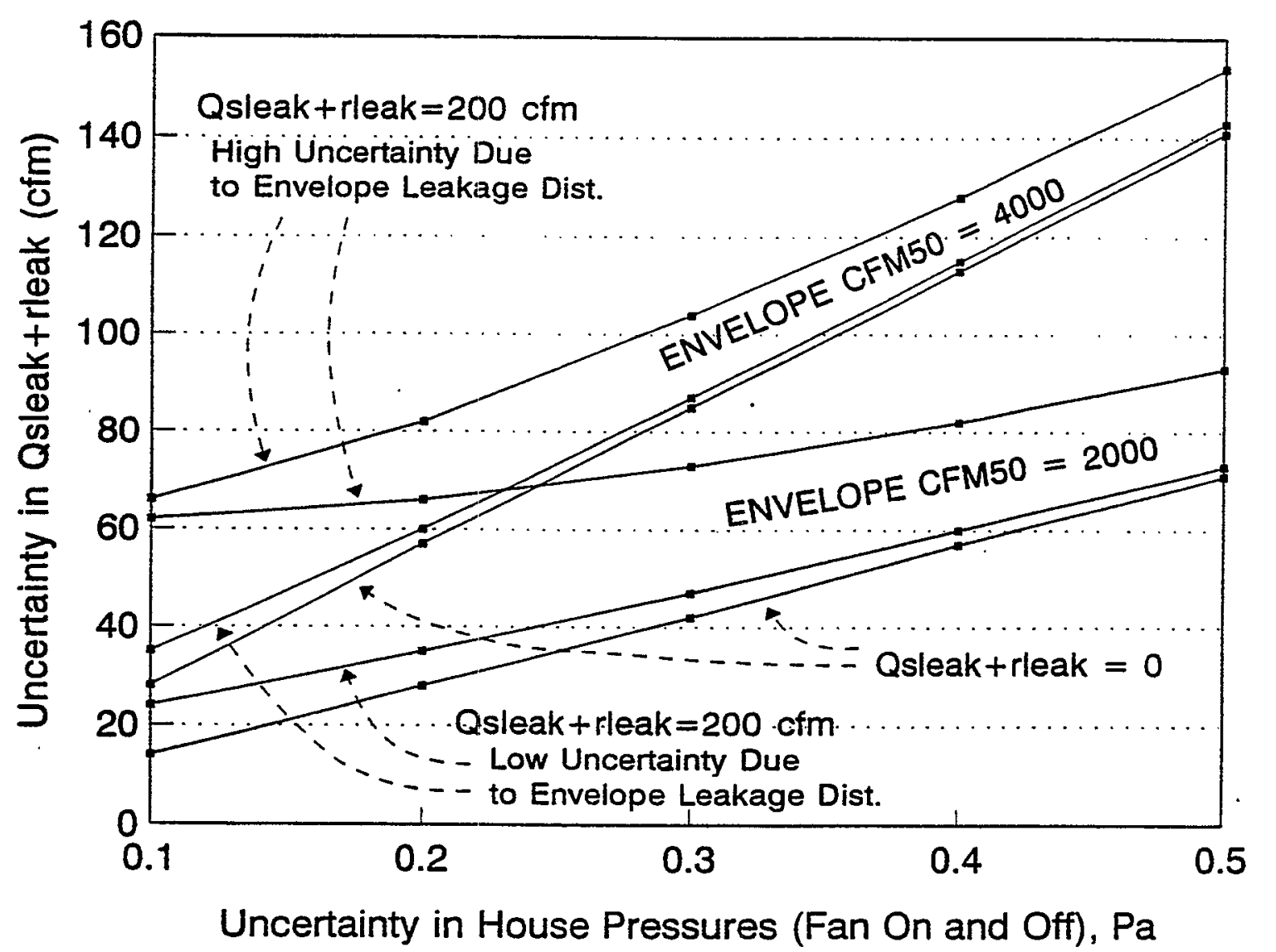

Figure 1. Uncertainty in Supply Minus Return Leakage from Dominant Duct Leakage Test $\left(\mathrm{Q}_{\text {sleaktriteal }}\right)$ as Function of Uncertainty in Measured House Pressures $\left(\Delta \mathrm{P}_{\text {on }}\right.$ and $\left.\Delta \mathrm{P}_{\text {off }}\right)$

Observed standard deviations for $\Delta \mathrm{P}_{\text {on }}$ and $\Delta \mathrm{P}_{\text {off }}$ tend to fall in the 0.5 to $1.0 \mathrm{~Pa}$ range under reasonably calm conditions and may be much higher when gusty winds are present. As currently written, ASHRAE Standard 152P calls for 20 measurements of $\triangle \mathrm{P}_{\text {on }}$ and 30 measurements of $\Delta \mathrm{P}_{\text {off }}$ so one would normally expect $95 \%$ confidence intervals in the $0.2-0.5 \mathrm{~Pa}$ range. Under the best of circumstances, a $0.5 \mathrm{~Pa}$ confidence interval would typically provide $\sim 60 \mathrm{cfm}$ uncertainty in $\mathrm{Q}_{\text {seaktrieas }}$, while under less favorable conditions (high envelope CFM50 combined with unbalanced duct leakage and high uncertainty due to envelope leakage distribution), the uncertainty can easily exceed $150 \mathrm{cfm}$. That level of uncertainty usually will be of little value for the data cross-check strategy, and additional data points will be needed. Clearly, the effort one is willing to expend on this will depend on the use to which the result is going to be put.

Researchers and others doing generic studies will want to take more data than diagnosticians desiring only a go/no-go decision on whether to do duct repairs in a specific house. Clearly, though, an attempt to reduce the uncertainty in $\Delta \mathrm{P}_{\text {on }}$ and $\Delta \mathrm{P}_{\text {off }}$ as low as $0.1 \mathrm{~Pa}$ will usually require a lot of data. 